\title{
Erratum to: On the Application of LES to Seal Geometries
}

\author{
J. Tyacke $\cdot$ R. Jefferson-Loveday $\cdot$ P. G. Tucker
}

Published online: 31 January 2014

(C) Springer Science+Business Media Dordrecht 2014

Erratum to: Flow, Turbulence and Combustion, 91(4) 827-848 (2013) DOI 10.1007/s10494-013-9480-x

R. Jefferson-Loveday and P. G. Tucker wish to acknowledge that code "B" in On the application of LES to seal geometries v.91, 4, 827-848 (2013) was substantially the NTS code written by Prof Strelets' group [1].

The code was shared in 2002 with a verbal agreement to allow joint research into 2003, and the agreement extended to help a student complete his doctorate. The code was subsequently used without permission and over repeated objections by Prof. M. Strelets and Dr. P. Spalart.

The authors apologise unreservedly for their failure to include this acknowledgement in their paper.

\section{References}

1. Travin, A., Shur, M., Strelets, M., Spalart, P.R.: Detached-Eddy simulations past a circular cylinder. Flow Turbul. Combust. 63, 293-313 (2000)

The online version of the original article can be found at http://dx.doi.org/10.1007/s10494-013-9480-x.

J. Tyacke $(\bowtie) \cdot$ R. Jefferson-Loveday $\cdot$ P. G. Tucker

University of Cambridge, Cambridge, UK

e-mail: jct53@cam.ac.uk 